\title{
COMPARATIVE EVALUATION OF WEAR RESISTANCE OF THREE BULK-FILL COMPOSITE AND SURFACE ROUGHNESS WITH ANTAGONIST HUMAN ENAMEL AND PORCELAIN
}

\author{
Ola Abd El Moniem Barakat*
}

\begin{abstract}
Objective: The aim of this study was to compare the two-body wear resistance and the surface roughness of three different bulk-fill composite resins and a conventional resin composite materials with against human enamel and porcelain.
\end{abstract}

Materials and methods: Eighty cylindrical specimens were fabricated from three bulk fill resin composites and one conventional composite : group I $(n=20)$ discs of Sonic, group II $(n=20)$ discs of Tetric Evoceram, group III $(n=20)$ Filtek and group IV $(n=20)$ Filtek Z250. All specimens were subjected to a programmable logic controlled equipment was used to record the two-body wear of tested composites. Enamel and porcelain were used as antagonists. Wear were determined by weight loss and images analysis software were evaluated the tested samples surface topography. All data were statistically analyzed by Kruskal-Wallis test followed by Dunn's and Wilcoxon signed-rank test.

Result: With enamel and porcelain antagonist; there was no statistically significant difference between weight loss and $\Delta \mathrm{Ra}$ of the four materials.

Porcelain antagonist showed statistically significantly higher weight loss than enamel antagonist with Tetric Evo Ceram, Sonic fill, Filtek as well as Z250 composite types;

While with Filtek, there was a statistically significant difference between $\Delta \mathrm{Ra}$ of the two $\operatorname{antagonists}(P$-value $=0.025$, Effect size $=2.714)$. Enamel showed an increase in roughness while porcelain showed a decrease in roughness.

Conclusion Nanofillers bulkfill resin composite did not significantly influence the wear resistance. Porcelain antagonist showed more wear than enamel antagonist. However, enamel showed decrease the roughness

KEYWORDS: Resin composite, wear resistance, enamel, porcelain fused to metal.

\section{INTRODUCTION}

Tooth wear is a multifactorial procedure based on pathologic or physiologic mechanisms which result to loss of tooth surface and leading to alterations in tooth anatomy. In physiological wear, abrasion tacks place gradually after deterioration of tooth surface during mastication when third object were present. (1) While, when opposing teeth are in direct contact during occlusal movements and

* Operative Dentistry, Faculty of Oral and Dental Medicine, Misr University for Science and Technology, Cairo,Egypt 
swallowing, attrition was the result, ${ }^{(2,3)}$ consequently, lose convexity of cusps and flattened of posterior teeth occurred and shortened of incisal edges and slightly loss of mammelons of anterior teeth. ${ }^{(4)}$

Clenching and bruxism regularly causing a pathological wear, which characterized by great attrition and tooth damage, with change of the path of masticatory movements. Also, affect the esthetic, and guidance function of teeth. Tempromandibular joint dysfunction and increasing stress on the masticatory system also associated by pathological wear. Advanced wear of dental restorative materials also can occur by attrition and abrasion, and the wear behave depends on the type of restorative material. ${ }^{(1)}$

Ideal restorative material should possess the similar wear property of human enamel. Esthetics and functional long term outcome of occlusal rehabilitations adversely affected by great abrasiveness and excessive wear. ${ }^{(5,6)}$

Since early of 1970 s resin composite materials were promoted for posterior teeth, the main apprehension of the dentist has been the wear resistance. Clinical trials of wear of resin composite materials showed significant results when compared with metallic restorations.

Advanced resin fillers and matrix of resin composite lead to observably improved resin materials for posterior restoration ${ }^{(7-11)}$

Recent generation of composite resin showed progress in performance in clinical studies over the years ${ }^{(12-19)}$

Heintze ${ }^{(20)}$ studied resin composite wear in vivo and in vitro and found that to achieve clinically continuing serviceability restorations of resin composites; it should be of high wear resistance.

Bulk-fill composites is a new generation of resin composite which conducted to the dental markets for saving time and costs ${ }^{(21)}$
The full-body bulk-fill composites can be regarded as the only true bulk filling type, since the whole restoration can be placed at once without requiring any coverage. These materials generally have higher filler loads, which create them highly viscous; for this reason, these materials are often referred to as paste-like bulk-fill composites. The higher filler load renders the surface more wear resistant and due to the associated viscous consistency, the surface is sculptable.

Occlusal and proximal wear are the most common causes for the failure of posterior composites. High wear resistance leads to an increased lifespan of the restoration, function, and color stability. Conversely, low wear resistance may lead to tooth migration, TMJ tenderness, and periodontal diseases. ${ }^{(22)}$

Wear resistance is one of the most difficult properties to evaluate in material sciences.

Clinical trials are mandatory for illustrating the multifaceted oral wear condition but also it is costly and time consuming. Variables such as masticatory forces or oral environments cannot be controlled.

Consequently, vitro tests considered as a practical way for evaluation the wear performance of any recent advanced materials. ${ }^{(23-25)}$ Different methods (25-27) and materials, ${ }^{(28,29)}$ have been recommended for the opposed natural cusps, but the requirement for a standardized of artificial abrader has been well defined. ${ }^{(30)}$ Even if enamel antagonists appear to realize in vivo similar circumstances in laboratory trials, the morphologic and structural differences of enamel confuse the standardization of wear evaluation .

The aim of this in vitro study was to assess the two-body wear resistance of three different bulkfill composite resin available in the market and one conventional resin composite with different compositions against, human enamel and porcelain. 


\section{MATERIALS AND METHODS}

Three bulk fill resin composite materials and one conventional were evaluated in this study. Bulk fill composites were Sonicfill, Tetric EvoCeram, and Filtek bulkfill. The conventional resin materials was Filtek Z250, their composition and manufacturer are listed in Table 1.

\section{Grouping of samples}

A total of eighty discs were prepared to determine the wear resistance of three different bulk fill resin composites and one conventional. They were divided into four groups, twenty specimens for each composite. Group I (Sonicfill), Group II (Tetric Evoceram), and Group III(Filtek bulkfill) and Group IV (Z250) .

Each group was subdivided into two subgroups, ten specimens each. The first subgroup was abraded against feldspathic porcelain, and the second subgroup was abraded against enamel natural teeth. Table 2

TABLE (1) Composition and manufacturer of the tested materials

\begin{tabular}{|c|c|c|}
\hline $\begin{array}{c}\text { Resin } \\
\text { Composite }\end{array}$ & Composition & Manufacturer \\
\hline $\begin{array}{l}\text { SonicFill } \\
\text { (Nanohybrid) }\end{array}$ & $\begin{array}{l}\text { The resin matrix } \\
\text { 3-trimethoxysilylpropyl methacrylate,ethoxylated } \\
\text { bisphenol-A-dimethacrylate (Bis-EMA), } \\
\text { bisphenol-A-bis-(2-hydroxy-3methacryloxypropyl)ether,triethyleneglycoldim } \\
\text { ethacrylate (TEGDMA) } \\
\text { The filler: Silicon dioxide, barium glass } 83 \% \mathrm{wt}(67 \% \mathrm{vol})\end{array}$ & $\begin{array}{l}\text { Kerr } \\
\text { Corporation }\end{array}$ \\
\hline $\begin{array}{l}\text { Tetric } \\
\text { EvoCeram } \\
\text { Bulk Fill } \\
\text { (Nanohybrid) }\end{array}$ & $\begin{array}{l}\text { The resin matrix UDMA, bisphenol Aglycidylmethacrylate (Bis-GMA) } \\
\text { The filler: } \\
\text { Barium glass,ytterbium trifluoride, } \\
\text { mixed oxide prepolymer } \\
\text { filler load } \\
82-84 \% \mathrm{wt}(64 \% \mathrm{vol}) \\
\text { Filler size } \\
550 \mathrm{~nm} \text { mean particle size; } \\
\text { range: } 40 \mathrm{~nm} \text { to } 3000 \mathrm{~nm}\end{array}$ & Ivoclar Vivadent, In \\
\hline $\begin{array}{l}\text { Filtek bulk- } \\
\text { fill, posterior } \\
\text { restorative } \\
\text { (Nanohybrid) }\end{array}$ & $\begin{array}{l}\text { The resin matrix AUDMA, UDMA and 1, 12-dodecane-DMA The filler: } \\
\text { non-agglomerated/non-aggregated } 20 \mathrm{~nm} \text { silica filler, a non-agglomerated/non- } \\
\text { aggregated } 4 \text { to } 11 \mathrm{~nm} \text { zirconia filler, anaggregated zirconia/silica cluster filler } \\
\text { (comprised of } 20 \mathrm{~nm} \text { silica } \\
\text { and } 4 \text { to } 11 \mathrm{~nm} \text { zirconia particles) and a ytterbium trifluoride filler consisting } \\
\text { of agglomerate } 100 \mathrm{~nm} \text { particles } \\
\text { filler load } \\
76.5 \% \mathrm{wt}(58.4 \% \mathrm{vol}) \\
\text { Filler size } \\
0.01 \text { to } 3.5 \mu \mathrm{m}\end{array}$ & $\begin{array}{l}\text { 3M/ESPE, St. Paul, MN, } \\
\text { USA }\end{array}$ \\
\hline $\begin{array}{l}\text { Filtek Z250 } \\
\text { ( MicroHybrid) }\end{array}$ & $\begin{array}{l}\text { The resin matrix } \\
\text { Bis-GMA, Bis-EMA, UDMA with small amount of TEGDMA } \\
\text { Filler } \\
\text { Silanized zirconia/silica particles } \\
\text { Filler load } \\
77 \% \text { wt } 57 \% \text { vol } \\
\text { Filler size:size range } 0.01 \text { to } 3.5 \mu \mathrm{m} \text {, average size } 0.6 \mu \mathrm{m}\end{array}$ & $\begin{array}{l}\text { 3M/ESPE, St. Paul, MN, } \\
\text { USA }\end{array}$ \\
\hline
\end{tabular}


TABLE (2) Materials, Composition, and manufacture of Antagonists.

\begin{tabular}{|l|l|l|l|}
\hline Material & Type & Composition & Manufacture \\
\hline PFM & $\begin{array}{l}\text { Feldspathic } \\
\text { Porcelain }\end{array}$ & $\begin{array}{l}\text { Fine crystalline powders of alumina, feldspar, and silica oxide } \\
\text { (or quartz, mixed with a flux of sodium or lithium carbonate. }\end{array}$ & Dentsply Caulk \\
\hline Natural Tooth Structure & Enamel & Calcium, Phosphate, Hydroxyapatite crystals, Water. & \\
\hline
\end{tabular}

\section{Specimens preparation:}

A standardized cylindrical mold measuring 10 $\mathrm{mm}$ thickness $\mathrm{x} 2 \mathrm{~mm}$ diameter was used to fabricated the bulk-fill and conventional resin composite specimens. A clear Mylar strip(Mylar Uni-strip, Caulk/ Dentsply, Milford, DE,USA) was placed on top of clean glass slab. The composite resin was packed in the mold using a plastic instrument. A clear Mylar strip and a 1-mm thickglass slide was placed on top of the specimen and then gently pressed to remove excess material on the mold. To prevent the formation of an oxygeninhibited layer and ensure smooth and flat surfaces, Mylar strips were placed on either side of the mold during curing. Each specimen was light cured using light emitting diode(LED) for 40 seconds(Demi Plus, Kerr, Orange Co., CA,USA) with a spectral range of $450-470 \mathrm{~nm}$ wavelength and $1200 \mathrm{~mW} / \mathrm{cm}^{2}$ intensity and then it was extruded from the mold by applying positive pressure using a pestle of $9 \mathrm{~mm}$ diameter to allow equal distribution of pressure.

In this study two different wear antagonists were used. Porcelain and Natural Teeth Table (2). The Porcelain and Natural teeth attached to the machine holder and tightened with a screw

\section{Wear testing:}

Prior to wear simulation, composites specimens were weighed (W1) in an Electronic Analytical Balance with an accuracy of 0.0001 gram. The two -body wear test was performed using a programmable logic controlled equipment (fourstation multimodal ROBOTA chewing simulator) integrated with thermo-cyclic protocol operated on servo-motor*( Figure1) (Model ACH-09075DC-T, AD-TECH TECHNOLOGY CO., LTD.)
Robota chewing simulator has four chambers mimicking the vertical and horizontal movements concurrently in a thermodynamic condition. Each of the chambers contains of an upper Jacob's chuck as an antagonist holder that can be tightened with a screw, and a lower plastic sample-holder in which the specimen can be inserted. (Figure 1)

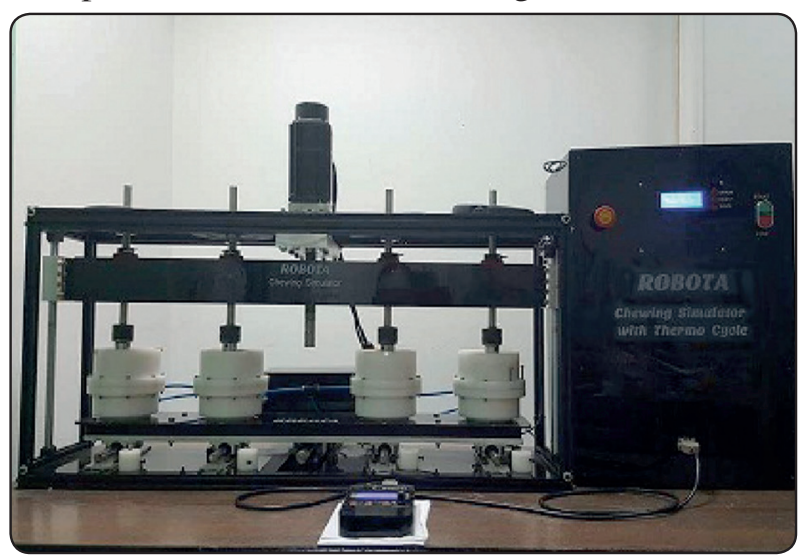

Fig. (1) Chewing simulator device ROBOTA

The specimens were inserted in Teflon housing in the lower sample-holder (Figure 2) while the antagonist were holed in upper Jacobs (Figure 3). A weight of $5 \mathrm{~kg}$, which is comparable to $49 \mathrm{~N}$ of chewing force, was exerted. The test was repeated 75,000 times to clinically simulate the 6 months chewing condition, accompanying thermo-cycling according to previous studies. ${ }^{(31)}$ (Table3)

TABLE (3)

\begin{tabular}{|l|l|}
\hline \multicolumn{2}{|l|}{ Wear test parameters } \\
\hline $\begin{array}{l}\text { Cold/hot bath temperature: } \\
5^{\circ} \mathrm{C} / 55^{\circ} \mathrm{C}\end{array}$ & Dwell time: $60 \mathrm{~s}$ \\
\hline Vertical movement: $1 \mathrm{~mm}$ & Horizontal movement: $2 \mathrm{~mm}$ \\
\hline Rising speed: $90 \mathrm{~mm} / \mathrm{s}$ & Forward speed: $90 \mathrm{~mm} / \mathrm{s}$ \\
\hline Descending speed: $40 \mathrm{~mm} / \mathrm{s}$ & Backward speed: $40 \mathrm{~mm} / \mathrm{s}$ \\
\hline Cycle frequency $1.6 \mathrm{~Hz}$ & Weight per sample: from $5 \mathrm{~kg}$ \\
\hline Torque; 2.4 N.m & \\
\hline
\end{tabular}


After wear simulation, the specimen was then weighed on the same balance* for measurement of weight after wear (W2). The loss of weight was calculated by subtraction of weight before and after wear tests (W1-W2) as this electronic balance had a fully automated calibration technology and a micro weighing scale.

The optical methods tend to fulfill the need for quantitative characterization of surface topography without contact. ${ }^{(31)}$

USB digital microscope with a built-in camera (Scope Capture Digital Microscope, Guangdong, China;) photographed composite samples. This microscope was connected with an IBM compatible personal computer using a fixed magnification of $120 \times$. The images with a resolution of $1,024 \times$ 1,280 pixels were recorded. Areas of roughness measurements were specified and standardized by image cropping to $350 \times 400$ pixels using Microsoft Office Picture Manager.

Final images were analyzed for roughness areas, using WSxM software (Ver5 develop 4.1, Nanotech, Electronica, SL). ${ }^{(32)}$ Finally, 3D image of the surface profile of composite samples was recorded using a digital image analysis system (Image 1.43U, National Institute of Health, and USA) (Figure 4).

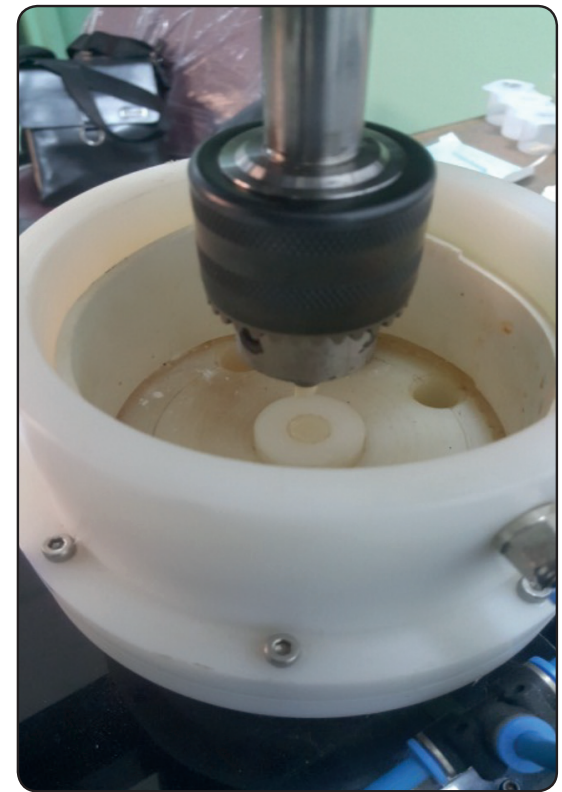

Fig. (2) Prepared sample of resin composite

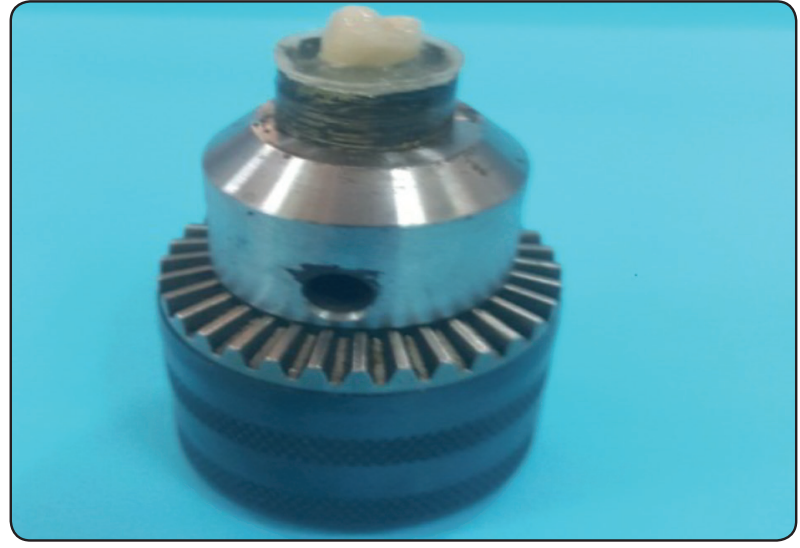

Fig. (3) antagonise holded in upper jacobe



Fig. (4) capture digital microscope

\section{Statistical Analysis}

Numerical data were explored for normality by checking the distribution of data and using tests of normality (Kolmogorov-Smirnov and Shapiro-Wilk tests). Data showed non-normal (non-parametric) distribution. Data were presented as mean, standard deviation (SD), median and range values. KruskalWallis test was used to compare between the materials. Dunn's test was used for pair-wise comparisons. Mann-Whitney U test was used to compare between the two antagonists. Wilcoxon signed-rank test was used to compare between the material and its antagonist. Statistical analysis was achieved with IBM SPSS Statistics for Windows, Version 23.0. Armonk, NY: IBM Corp. The level of significance was set at $\mathrm{P} \leq 0.05$. 


\section{RESULTS}

\section{Weight loss}

\section{Comparison between materials}

With enamel antagonist; there was no significant difference between weight losses of the four materials $(P$-value $=0.269$, Effect size $=0.116)$.

Similarly, with porcelain antagonist; there was no significant difference between weight losses of the four materials $(P$-value $=0.127$, Effect size $=0.337)$.

\section{Comparison between material weight losses with different antagonists}

With Tetric Evo Ceram, Sonic fill, Filtek as well as Z250 composite types; porcelain antagonist showed statistically significantly higher weight loss than enamel antagonist $(P$-value $<0.001$, Effect size $=4.932),(P$-value $<0.001$, Effect size $=5.806)$, $(P$-value $=0.001$, Effect size $=1.748)$ and $(P$-value $=0.003$, Effect size $=1.520)$, respectively .

TABLE (4) Descriptive statistics and results of Kruskal-Wallis test for comparisons between weight losses of the different materials with each antagonist

\begin{tabular}{|c|c|c|c|c|c|c|}
\hline Antagonist type & Tetric Evo Ceram & Sonic fill & Filtek & $\mathrm{Z} 250$ & $P$-value & $\begin{array}{c}\text { Effect } \\
\text { size (Eta } \\
\text { squared) }\end{array}$ \\
\hline \multicolumn{7}{|l|}{ Enamel } \\
\hline Mean (SD) & $0.00017(0.00015)$ & $0.00057(0.00021)$ & $0.00053(0.00059)$ & $0.00023(0.00023)$ & \multirow{2}{*}{0.269} & \multirow{2}{*}{0.116} \\
\hline Median (Range) & $0.0002(0-0.0003)$ & $\begin{array}{c}0.0005(0.0004- \\
0.0008)\end{array}$ & $\begin{array}{c}0.0003(0.0001- \\
0.0012)\end{array}$ & $\begin{array}{c}0.0001(0.0001- \\
0.0005)\end{array}$ & & \\
\hline \multicolumn{7}{|l|}{ Porcelain } \\
\hline Mean (SD) & $0.00107(0.00021)$ & $0.00237(0.00031)$ & $0.00233(0.00103)$ & $0.00137(0.00075)$ & \multirow{2}{*}{0.127} & \multirow{2}{*}{0.337} \\
\hline Median (Range) & $\begin{array}{c}0.001(0.0009- \\
0.0013)\end{array}$ & $\begin{array}{c}0.0023(0.0021- \\
0.0027)\end{array}$ & $\begin{array}{c}0.0026(0.0012- \\
0.0032)\end{array}$ & $\begin{array}{c}0.0014(0.0006- \\
0.0021)\end{array}$ & & \\
\hline
\end{tabular}

*: Significant at $P \leq 0.05$

TABLE (5) Descriptive statistics and results of Mann-Whitney U test for comparisons between each material's weight loss with different antagonists

\begin{tabular}{|c|c|c|c|c|}
\hline Antagonist type & Tetric Evo Ceram & SonicFill & Filtek & $\mathrm{Z} 250$ \\
\hline \multicolumn{5}{|l|}{ Enamel } \\
\hline Mean (SD) & $0.00017(0.00015)$ & $0.00057(0.00021)$ & $0.00053(0.00059)$ & $0.00023(0.00023)$ \\
\hline Median (Range) & $0.0002(0-0.0003)$ & $0.0005(0.0004-0.0008)$ & $0.0003(0.0001-0.0012)$ & $0.0001(0.0001-0.0005)$ \\
\hline \multicolumn{5}{|l|}{ Porcelain } \\
\hline Mean (SD) & $0.00107(0.00021)$ & $0.00237(0.00031)$ & $0.00233(0.00103)$ & $0.00137(0.00075)$ \\
\hline Median (Range) & $0.001(0.0009-0.0013)$ & $0.0023(0.0021-0.0027)$ & $0.0026(0.0012-0.0032)$ & $0.0014(0.0006-0.0021)$ \\
\hline$P$-value & $<0.001 *$ & $<0.001 *$ & $0.001 *$ & $0.003 *$ \\
\hline Effect size $(d)$ & 4.932 & 5.806 & 1.748 & 1.520 \\
\hline
\end{tabular}




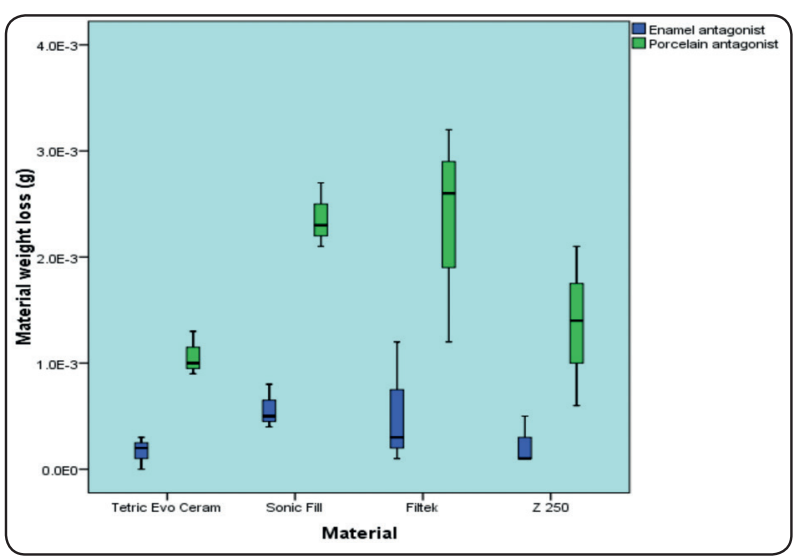

Fig. (5) Box plot representing median and range values for weight losses of the different materials

\section{Comparison between weight losses of each ma- terial with its antagonist}

With all materials; there was no statistically significant difference between weight losses of each material and its antagonist

\section{Change in surface roughness $(\Delta \mathrm{Ra})$}

\section{Comparison between materials}

With enamel antagonist; there was no statistically significant difference between $\Delta \mathrm{Ra}$ of the four materials $(P$-value $=0.062$, Effect size $=0.542)$.

TABLE (6) Descriptive statistics and results of Wilcoxon signed-rank test for comparisons between weight losses of each material with its antagonist

\begin{tabular}{|c|c|c|c|c|}
\hline Material and Antagonist & Material weight loss & Antagonist weight loss & $P$-value & Effect size $(r)$ \\
\hline \multicolumn{5}{|c|}{ Tetric Evo Ceram vs. Enamel } \\
\hline Mean (SD) & $0.00017(0.00015)$ & $0.00883(0.00045)$ & \multirow{2}{*}{0.109} & \multirow[t]{2}{*}{0.904} \\
\hline Median (Range) & $0.0002(0-0.0003)$ & $0.0088(0.0084-0.0093)$ & & \\
\hline \multicolumn{5}{|l|}{ Sonic Fill vs. Enamel } \\
\hline Mean (SD) & $0.00057(0.00021)$ & $0.0066(0.00072)$ & \multirow{2}{*}{0.102} & \multirow[t]{2}{*}{0.943} \\
\hline Median (Range) & $0.0005(0.0004-0.0008)$ & $0.0068(0.0058-0.0072)$ & & \\
\hline \multicolumn{5}{|l|}{ Filtek vs. Enamel } \\
\hline Mean (SD) & $0.00053(0.00059)$ & $0.00287(0.00006)$ & \multirow{2}{*}{0.109} & \multirow[t]{2}{*}{0.904} \\
\hline Median (Range) & $0.0003(0.0001-0.0012)$ & $0.0029(0.0028-0.0029)$ & & \\
\hline \multicolumn{5}{|l|}{ Z250 vs. Enamel } \\
\hline Mean (SD) & $0.00023(0.00023)$ & $0.02143(0.00085)$ & \multirow{2}{*}{0.109} & \multirow[t]{2}{*}{0.904} \\
\hline Median (Range) & $0.0001(0.0001-0.0005)$ & $0.0214(0.0206-0.0223)$ & & \\
\hline \multicolumn{5}{|c|}{ Tetric Evo Ceram vs. Porcelain } \\
\hline Mean (SD) & $0.00107(0.00021)$ & $0.00877(0.00025)$ & \multirow{2}{*}{0.109} & \multirow[t]{2}{*}{0.904} \\
\hline Median (Range) & $0.001(0.0009-0.0013)$ & $0.0088(0.0085-0.009)$ & & \\
\hline \multicolumn{5}{|l|}{ Sonic Fill vs. Porcelain } \\
\hline Mean (SD) & $0.00237(0.00031)$ & $0.00027(0.00015)$ & \multirow{2}{*}{0.109} & \multirow[t]{2}{*}{0.904} \\
\hline Median (Range) & $0.0023(0.0021-0.0027)$ & $0.0003(0.0001-0.0004)$ & & \\
\hline \multicolumn{5}{|l|}{ Filtek vs. Porcelain } \\
\hline Mean (SD) & $0.00233(0.00103)$ & $0.001(0.00125)$ & \multirow{2}{*}{0.109} & \multirow[t]{2}{*}{0.904} \\
\hline Median (Range) & $0.0026(0.0012-0.0032)$ & $0.0006(0-0.0024)$ & & \\
\hline \multicolumn{5}{|l|}{ Z250 vs. Porcelain } \\
\hline Mean (SD) & $0.00137(0.00075)$ & $0.0069(0.0007)$ & \multirow{2}{*}{0.109} & \multirow[t]{2}{*}{0.904} \\
\hline Median (Range) & $0.0014(0.0006-0.0021)$ & $0.0069(0.0062-0.0076)$ & & \\
\hline
\end{tabular}

\footnotetext{
*: Significant at $P \leq 0.05$
} 
Similarly, with porcelain antagonist; there was no statistically significant difference between $\Delta \mathrm{Ra}$ of the four materials $(P$-value $=0.259$, Effect size $=0.128$ ).

\section{Comparison between antagonists}

With Tetric Evo Ceram; there was no statistically significant difference between $\Delta \mathrm{Ra}$ of the two antagonists $(P$-value $=0.084$, Effect size $=0.552)$.

Similarly with Sonic Fill; there was no statistically significant difference between $\Delta \mathrm{Ra}$ of the two antagonists $(P$-value $=0.058$, Effect size $=$ $1.643)$.

While with Filtek, there was a statistically significant difference between $\Delta \mathrm{Ra}$ of the two antagonists $(P$-value $=0.025$, Effect size $=2.714)$. Enamel showed an increase in roughness while porcelain showed a decrease in roughness.

And finally with Z250 composite, there was no statistically significant difference between $\Delta \mathrm{Ra}$ of the two antagonists $(P$-value $=0.052$, Effect size $=$ $1.800)$.

TABLE (7) Descriptive statistics and results of Kruskal-Wallis test for comparisons between $\Delta \mathrm{Ra}$ of the different materials with each antagonist

\begin{tabular}{|c|c|c|c|c|c|c|}
\hline Antagonist type & Tetric Evo Ceram & Sonic Fill & Filtek & $\mathrm{Z} 250$ & $P$-value & $\begin{array}{c}\text { Effect size } \\
\text { (Eta squared) }\end{array}$ \\
\hline \multicolumn{7}{|l|}{ Enamel } \\
\hline Mean (SD) & $0.0015(0.002)$ & $-0.0033(0.0009)$ & $0.0003(0.001)$ & $0.002(0.0018)$ & \multirow{2}{*}{0.062} & \multirow{2}{*}{0.542} \\
\hline Median (Range) & $\begin{array}{c}0.0013(-0.0004- \\
0.0035) \\
\end{array}$ & $\begin{array}{c}-0.0028(-0.0043- \\
-0.0028) \\
\end{array}$ & $\begin{array}{c}0.0005(-0.0008- \\
0.0012)\end{array}$ & $\begin{array}{c}0.0018(0.0003- \\
0.0038)\end{array}$ & & \\
\hline \multicolumn{7}{|l|}{ Porcelain } \\
\hline Mean (SD) & $0.0005(0.0016)$ & $-0.001(0.0014)$ & $-0.0016(0.0007)$ & $-0.0016(0.002)$ & \multirow{2}{*}{0.259} & \multirow[t]{2}{*}{0.128} \\
\hline Median (Range) & $\begin{array}{c}0.0008(-0.0012- \\
0.002)\end{array}$ & $\begin{array}{c}-0.0015(-0.0021- \\
0.0005)\end{array}$ & $\begin{array}{c}-0.0016(-0.0022- \\
-0.0009)\end{array}$ & $\begin{array}{c}-0.0019(-0.0034- \\
0.0005)\end{array}$ & & \\
\hline
\end{tabular}

*: Significant at $P \leq 0.05$

Table 8: Descriptive statistics and results of Mann-Whitney $U$ test for comparisons between $\Delta R a$ of each material with the different antagonists

\begin{tabular}{lcccc}
\hline Antagonist type & Tetric Evo Ceram & Sonic Fill & Filtek & Z250 \\
\hline Enamel & & & & $0.0003(0.001)$ \\
Mean (SD) & $0.0015(0.002)$ & $-0.0033(0.0009)$ & $0.002(0.0018)$ \\
Median (Range) & $0.0013(-0.0004-0.0035)$ & $-0.0028(-0.0043-$ & $0.0005(-0.0008-0.0012)$ & $0.0018(0.0003-0.0038)$ \\
\hline Porcelain & & $-0.0028)$ & $-0.0016(0.0007)$ & $-0.0016(0.002)$ \\
Mean (SD) & $0.0005(0.0016)$ & $-0.001(0.0014)$ & $-0.0016(-0.0022-$ & $-0.0019(-0.0034-0.0005)$ \\
Median (Range) & $0.0008(-0.0012-0.002)$ & $-0.0015(-0.0021-$ & $-0.0009)$ & 0.052 \\
\hline$P$-value & 0.084 & $0.0005)$ & $0.025 *$ & 1.800 \\
\hline Effect size (Eta squared) & 0.552 & 0.058 & 2.714 & 0 \\
\hline
\end{tabular}

*: Significant at $P \leq 0.05$ 


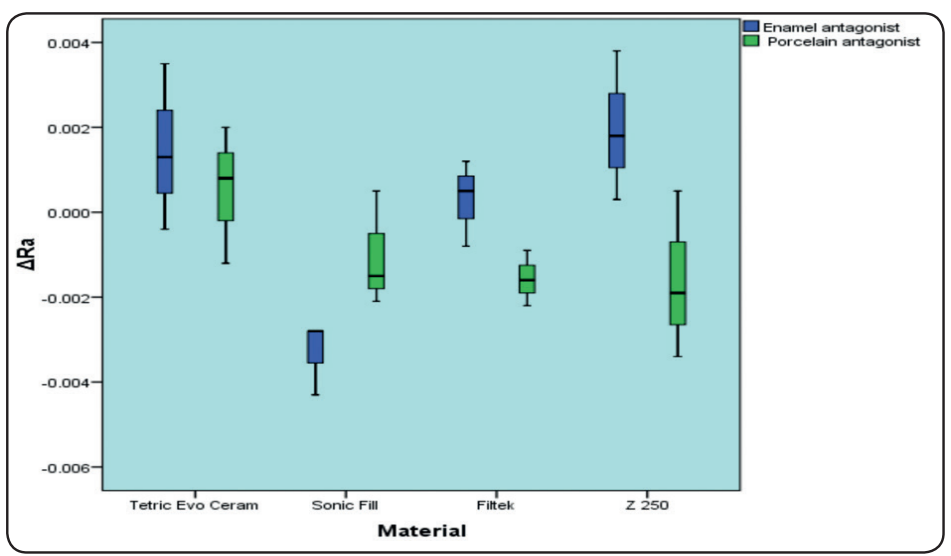

\section{Comparison between $\mathrm{ARa}$ of each material with its antagonist}

With all materials; there was no statistically significant difference between $\Delta \mathrm{Ra}$ of each material and its antagonist.

Fig. (6): Box plot representing median and range values for $\Delta \mathrm{Ra}$ of the different groups

TABLE (9) Descriptive statistics and results of Wilcoxon signed-rank test for comparisons between $\Delta$ Ra of each material with its antagonist

\begin{tabular}{|c|c|c|c|c|}
\hline Material and Antagonist & Material $\Delta \mathrm{Ra}$ & Antagonist $\Delta \mathrm{Ra}$ & $P$-value & Effect size $(r)$ \\
\hline \multicolumn{5}{|c|}{ Tetric Evo Ceram vs. Enamel } \\
\hline Mean (SD) & $0.0015(0.002)$ & $0.0011(0.0016)$ & \multirow[t]{2}{*}{0.414} & \multirow[t]{2}{*}{0.471} \\
\hline Median (Range) & $0.0013(-0.0004-0.0035)$ & $0.0002(0.0002-0.0029)$ & & \\
\hline \multicolumn{5}{|l|}{ Sonic Fill vs. Enamel } \\
\hline Mean (SD) & $-0.0033(0.0009)$ & $0.0007(0.0016)$ & \multirow[t]{2}{*}{0.109} & \multirow[t]{2}{*}{0.904} \\
\hline Median (Range) & $-0.0028(-0.0043--0.0028)$ & $0.0004(-0.0007--0.0025)$ & & \\
\hline \multicolumn{5}{|l|}{ Filtek vs. Enamel } \\
\hline Mean (SD) & $0.0003(0.001)$ & $-0.0015(0.0019)$ & \multirow{2}{*}{0.109} & \multirow[t]{2}{*}{0.904} \\
\hline Median (Range) & $0.0005(-0.0008-0.0012)$ & $-0.0014(-0.0035-0.0003)$ & & \\
\hline \multicolumn{5}{|l|}{ Z250 vs. Enamel } \\
\hline Mean (SD) & $0.002(0.0018)$ & $-0.001(0.001)$ & \multirow{2}{*}{0.109} & \multirow[t]{2}{*}{0.904} \\
\hline Median (Range) & $0.0018(0.0003-0.0038)$ & $-0.0005(-0.0022--0.0003)$ & & \\
\hline \multicolumn{5}{|c|}{ Tetric Evo Ceram vs. Porcelain } \\
\hline Mean (SD) & $0.0005(0.0016)$ & $-0.0011(0.0013)$ & \multirow{2}{*}{0.285} & \multirow[t]{2}{*}{0.617} \\
\hline Median (Range) & $0.0008(-0.0012-0.002)$ & $-0.0011(-0.0024--0.0002)$ & & \\
\hline \multicolumn{5}{|l|}{ Sonic Fill vs. Porcelain } \\
\hline Mean (SD) & $-0.001(0.0014)$ & $0.0017(0.0007)$ & \multirow{2}{*}{0.109} & \multirow[t]{2}{*}{0.904} \\
\hline Median (Range) & $-0.0015(-0.0021-0.0005)$ & $0.0015(0.0011-0.0024)$ & & \\
\hline \multicolumn{5}{|l|}{ Filtek vs. Porcelain } \\
\hline Mean (SD) & $-0.0016(0.0007)$ & $0.0003(0.0027)$ & \multirow{2}{*}{0.285} & \multirow[t]{2}{*}{0.617} \\
\hline Median (Range) & $-0.0016(-0.0022--0.0009)$ & $-0.0005(-0.0018-0.0033)$ & & \\
\hline \multicolumn{5}{|l|}{ Z250 vs. Porcelain } \\
\hline Mean (SD) & $-0.0016(0.002)$ & $0.0004(0.001)$ & \multirow{2}{*}{0.109} & \multirow[t]{2}{*}{0.904} \\
\hline Median (Range) & $-0.0019(-0.0034-0.0005)$ & $-0.0001(-0.0003-0.0015)$ & & \\
\hline
\end{tabular}

*: Significant at $P \leq 0.05$ 


\section{DISCUSSION}

Wear resistance is an essential factor to be measured when selecting proper restorative material for clinical use. Adequate wear resistance and reducing of abrasiveness of restorative material ideally, be closely as possible to the characteristic of natural enamel. Thus wear behavior in the oral cavity could be evaluated.

Wear is commonly a slow process. The clinical appearance of wear displays the presence of a flat distinct facet on the restorative material. As the wear progresses, there is an affinity toward reduction of the cusp height and the flattening of the occlusal planes which may lead to loss of vertical dimension. A well-distributed occlusion has a significant effect on the wear progression.

The most important changes in recent composites in latest years were changes of the filler system. The size of filler particles incorporated into the resin matrix of recent composites has continuously decreased, resulting in nanohybrid and nanofilled materials with improved material properties.

Previously, several trials for wear testing devices have been established to simulator the clinical wear resistance. However these devices cannot be efficient in perfectly clinical evaluation of restorative materials.

Clinical studies are the gold standard methods for evaluation the properties of a new material. A 3 -years clinical study was assessed to evaluate the clinical performance of microhybrid composite (Z100, 3M ESPE, USA) against nano hybrid composite (Filtek Supreme). The material loss through wear was evaluated by a 3D laser scanning device and the vertical loss was measured of the microhybrid composite (Z100), and nano hybrid composite (Filtek Supreme). The result were $64 \pm$ $26 \mu \mathrm{m}$ and $75 \pm 27 \mu \mathrm{m}$, respectively, after 3 years of clinical service. However, there were no significant differences between the two materials for other evaluative indices considered, including wear. ${ }^{(33)}$
In a 4-year clinical assessment of a fine hybrid and nanohybrid composite resin using the modified USPHS (United States Public Health Service) criteria ${ }^{(34)}$, and In a 2-year clinical evaluation of a fine-particle hybrid, and nanofiller resin composite with the Ryge criteria, ${ }^{(35)}$ none of the evaluative indices showed any significant difference between the two groups. The results of these clinical studies are in agreement with the results of the current study.

In the present study there was no statistically significant difference between weights losses of the four resin composite materials tested with enamel antagonist explaining for this finding that the higher filler content shows the lesser wear. Thus, wear of composites is recognized to depend on filler particle-related features, particularly on the concentration and size of the filler reinforcement and resin formulation. Finer particles for a fixedvolume-fraction of filler have been documented to result in decreased inter particle spacing and thereby reducing wear. This result is consistent with the reports of several studies ${ }^{(36-39)}$

The maximum size of the filler in composite resin is $50 \mu \mathrm{m}$. In Tetric Evo Ceram Bulk-fill the largest particles of the inorganic fillers measure $3 \mu \mathrm{m}$. In the polymerized form, they act like the smaller inorganic primary particles. The larger filler particles do not protrude from the surface. Composite wear resistance and its excellent polishing properties are responsible of the fine primary particles of the fillers which are showed in smooth surface texture and high luster.

As for the resin formulation, the studies has shown that increasing resin viscosity generally lowers the wear resistance. ${ }^{(40)}$ Due to the higher filler content of bulk-fill composites, greater will be the depth of cure which reduced volume of resin matrix for polymerization and increased hardness. ${ }^{(41)}$

In the present study, it was found that Tetric Evo Ceram, Sonic fill, Filtek as well as Z250 composite types; showed statistically significantly higher weight loss with porcelain antagonist than enamel 
antagonist. This finding could be explained by difference in the friction coefficient, which is higher in the porcelain, this finding is consistent with Ghazal etal. ${ }^{(41)}$

Surface roughness is a major surface property of composites resin restorative material. It has been recognized as a factor of high clinical application for wear resistance, material discoloration, gingival inflammation, plaque accumulation, and surface gloss.

Surface roughness after simulated wear was mainly associated with filler size and distribution of composite resins. Microhybrid resin composite contain combinations of submicroscopic and microscopic sized particles. While Nanofilled composites contain both discrete nanocluster and nanomer particles ${ }^{(42)}$

In the present study there was no statistically significant difference between the four resin composite materials with the two antagonists (enamel \& porcelain). This may be improved the polishability of nano-fillers in such composite resin. The smaller the filler size, the lower the degree of filler pluck-out, therefore the better the polishability. ${ }^{(43)}$

In addition this result in agreement with Mitra et $\mathrm{al}^{(44)}$ who stated that smooth wear surface of nanofilled composite were induced by breaking out of individual primary particles or parts of the clusters rather than by debonding of larger particles.

\section{CONCLUSION}

With the limitation of this study, the tested bulkfill resin composite showed improvement in surface roughness, while nano filler composite did not significantly affect wear resistance. Different results may be obtained by using 3-body wear test with other antagonists. Testing in more oral simulation environments is needed to full characterize the wear behavior of restorative materials and to reach clinically relevant conclusion.

\section{REFERENCE}

1 D’Arcangelo C, Vanini L, Rondoni GD, Pirani M, Vadini M, Gattone M, De Angelis F. Wear properties of a novel resin composite compared to human enamel and other restorative materials. Oper Dent 2014;39:612-8.

2. Stober T, Lutz T, Gilde H, Rammelsberg P. Wear of resin denture teeth by two-body contact. Dent Mater 2006;22:243-9.

3. Ghazal M, Yang B, Ludwig K, Kern M. Two-body wear of resin and ceramic denture teeth in comparison to human enamel. Dent Mater 2008;24:502-7.

4. Oh WS, Delong R, Anusavice KJ. Factors affecting enamel and ceramic wear: a literature review. J Prosthet Dent 2002;87:451-9-

5. Yip KH, Smales RJ, Kaidonis JA. Differential wear of teeth and restorative materials: clinical implications. Int J Prosthodont 2004;17:350-6.

6. Zeng J, Sato Y, Ohkubo C, Hosoi T. In vitro wear resistance of three types of composite resin denture teeth. J Prosthet Dent 2005;94:453-7.

7. Barkmeier WW, Latta MA, Wilwerding TM, \& Blake $\operatorname{SM}(2001)$ Wear assessment of high viscosity and convention- al composite restorative materials Operative Dentistry 26(2)152-156.

8. Nagarajan VS, Jahanmir S, \& Thompson VP (2004) In vitro contact wear of dental composites Dental Materials 20(1) 63-71.

9. Zantner C, Kielbassa AM, Martus P, \& Kunzelmann KH (2004) Sliding wear of 19 commercially available composites and compomers Dental Materials 20(3) 277-285.

10. Ferracane JL (2006) Is the wear of dental composites still a clinical concern? Is there still a need for in vitro wear simulating devices? Dental Materials 22(8) 689-692.

11. Heintze SD, Barkmeier WW, Latta MA, \& Rousson V(2011) Round robin test: Wear of nine restorative materials in six different wear simulators-Supplement to the round robin test of 2005 Dental Materials 27(2) e1-e9

12. Barkmeier WW, Latta MA, Erickson RL, \& Lambrechts $\mathrm{P}$ (2004) Comparison of laboratory and clinical wear rates of resin composites Quintessence International 35(4) 269-274. 
13. Sarrett DC, Brooks CN, \& Rose JT (2006) Clinical performance evaluation of a packable posterior composite in bulk-cured restorations Journal of the American Dental Association 137(1) 71-80.

14. Barkmeier WW, Erickson RL, Latta MA, \& Wilwerding TM (2008) Wear simulation of resin composites and the relationship to clinical wear Operative Dentistry 33(2) 177-182.

15. Palaniappan S, Bharadwaj D, Mattar DL, Peumans M, Van Meerbeek B, \& Lambrechts P (2009) Three-year randomized clinical trial to evaluate the clinical performance and wear of a nanocomposite versus a hybrid composite Dental Materials 25(11) 1302-1314.

16. Opdam, NJ, Bronkhorst BA, \& Huysmans MC (2010) 12-year survival of composite vs. amalgam restorations Journal of Dental Research 89(10) 1063-1067.

17. Palaniappan S, Bharadwaj D, Mattar DL, Peumans M, Van Meerbeek B, \& Lambrechts P (2011) Nanofilled and microhybrid composite restorations: Five-year clinical wear performances Dental Materials 27(7) 692-700.

18. Da Rosa Rodolpho PA, Donassollo TA, Cenci MS, Logue ŕcio AD, Moraes RR, Bronkhorst EM, Opdam NJ,\& Demarco FF (2011) 22-year clinical evaluation of the performance of two posterior composites with different filler characteristics Dental Materials27(10)955-963.

19. Heintze SD, Faouri M, Rousson V, \& Ozcan M (2012) Correlation of wear in vivo and six laboratory wear methods Dental Materials 28(9) 961-973

20. Heintze SD. How to qualify and validate wear simulation devices and methods. Dent Mater 2006; 22:712-34; https:// doi.org/10.1016/j.dental.2006.02.002

21. Annelies Van Ende, Jan De Munck, Diogo Pedrollo Lise, Bart Van Meerbeek. Bulk-Fill Composites: A Review of the current literature. J Adhes Dent 2017; 19: 95-109

22. Arvind Kumar,A. Sheerin Sarthaj, and Dipak S. Majumder. Comparative evaluation of wear resistance of cast gold with bulk-fill composites an in vitro study.J Conserv Dent 2018;21(3):302-305-

23. Heintze SD, Zappini G, Rousson V. Wear of ten dental restorative materials in five wear simulators-results of a round robin test. DentMater; 2005 (21):30417.

24. Heintze SD. How to qualify and validate wear simulation devices and methods. Dent Mater 2006;22:712-34.
25. Heintze SD, Zellweger G, Cavalleri A, Ferracane J. Influence of the antagonist material on the wear of different composites using two different wear simulation methods Dent Mater 2006;22:166-75.

26. O'Kray HP, O’Brien WJ. In vitro human enamel wear by a hydrated highalkali porcelain. Quintessence Int 2005;36:617-22.

27. Stober T, Lutz T, Gilde H, Rammelsberg P. Wear of resin denture teeth by two-body contact. Dent Mater 2006;22:243-9.

28. Ghazal M, Kern M. The influence of antagonistic surface roughness on the wear of human enamel and nanofilled composite resin artificial teeth. J Prosthet Dent 2009;101:342-9.

29. Ghazal M, Albashaireh ZS, Kern M. Wear resistance of nanofilled composite resin and feldspathic ceramic artificial teeth. J Prosthet Dent 2008;100:441-8.

30. Heintze SD, Cavalleri A, Forjanic M, Zellweger G, Rousson V. Wear of ceramic and antagonistea systematic evaluation of influencing factors in vitro. Dent Mater 2008;24:433-49.

31. Abouelatta OB. 3D surface roughness measurement using a light sectioning vision system. Vol 1. London,United Kingdom: Proceedings of the World Congress on Engineering; 2010.

32. Horcas I, Fernandez R, Gomez JM, Colchero J, GomezHerrero J, Baro AM. WSXM: a software for scanning probe microscopy and a tool for nanotechnology. Rev Sci Instrum 2007;78:013705.https://doi.org/10.1063/1.2432410

33. Palaniappan S, Bharadwai D, Mattar DL et al. Threeyear randomized clinical trial to evaluate the clinical performance and wear of a nano-composite versus a hybrid composite. Dent Mater 2009;25:1302-1314.

34. Krämer N, Reinelt C, Richter G et al. Nanohybrid vs. fine hybrid composite in Class II cavities: Clinical results and margin analysis after four years. Dent Mater 2009;25:750 759

35. Ernst CP, Brandenbusch M, Meyer G et al. Two-year clinical perfor-mance of a nanofiller vs a fine-particle hybrid resin composite. Clin Oral Investig 2006;10:119-125.

36. Turssi CP, De Moraes Purquerio B, Serra MC. Wear of dental resin composites: Insights into underlying processes and assessment methods - A review. J Biomed Mater Res B Appl Biomater. 2003;65:280-5. [PubMed] [Google Scholar] 
37. Lambrechts P, Braem M, Vuylsteke-Wauters M, Vanherle G. Quantitative in vivo wear of human enamel. J Dent Res. 1989;68:1752-4. [PubMed] [Google Scholar]

38. Söderholm KJ, Richards ND. Wear resistance of composites: A solved problem? Gen Dent. 1998;46:256-63. [PubMed] [Google Scholar]

39. Turssi CP, Ferracane JL, Vogel K. Filler features and their effects on wear and degree of conversion of particulate dental resin composites. Biomaterials. 2005;26:4932-7. [PubMed] [Google Scholar]

40. Musanje L, Ferracane JL, Ferracane LL. Effects of resin formulation and nanofiller surface treatment on in vitro wear of experimental hybrid resin composite. J Biomed Mater Res B Appl Biomater. 2006;77:120-5. [PubMed] [Google Scholar]
41. Ghazal M, yang b, Ludwig k, kern m. two-body wear of resin and ceramic denture teeth in comparison to human enamel.Dent mater 2008;24:502-7.

42. Han JM, Zhang H, Choe H S, LIN H, Zheng G and Hong G. Abrasive wear and surface roughness of contemporary dental composite resin. Dental Materials Journal 2014; 33(6): 725-732.

43. Jung M, Sehr K, Klimek J. surface texture of four nanofilled and one hybrid composite after finishing. Oper Dent 2007;32:45-52.

44. Mitra SB, Wu D, Holmes BN. An application of nanotechnology in advanced dental materials. J Am Dent Assoc 2003; 134: 1382-1390. 